\title{
Have thirteen beggars been killed by a serial killer?
}

\author{
Vidanapathirana M \\ Department of Forensic Medicine, Faculty of Medical Sciences, University of Sri Jayewardenepura, \\ Nugegoda, Sri Lanka
}

Correspondence: Dr. Muditha Vidanapathirana;

Mobile: +94 772988227; e-mail: mudithavidana@gmail.com

\begin{abstract}
Introduction: From 2010-2011, several murders of beggars were reported from Colombo and suburb. The motive of such killings was not obvious and some parties suspected an attack targeting beggars by an organized group.
\end{abstract}

Objective: To analyse the medico-legal aspects of the series of killing.

Methods: Data of beggars who had been killed, serially, under similar circumstances in Colombo and suburbs were collected from January 2010 to December 2011.

Results: There were 14 murders (12 males) in 9 towns. The bodies were left on the location of killing without being moved. The causes of death had been blunt force trauma to head. No suspects were arrested. Sole eye witness confirmed the presence of 'rituals' and 'cooling-off period' in suspect. In November 2011, a beggar was arrested while attempting to kill another beggar when the latter was a sleep. The suspect was produced for medico-legal examination and later referred to a Psychiatrist. He was diagnosed to have anti-social traits. On a subsequent day, he admitted that he had murdered altogether 14 beggars. He had shown all the crime scenes to the investigators. He was sent for inward psychiatric treatment and is awaiting trial.

Conclusions: Usually serial killers are males with past criminal records who kill strangers, perform 'rituals', leave 'signature', display the dead bodies and remove souvenirs. All above characteristics except the last two were evident in this case. Fourteen independent, planned murders with potential "cooling-off periods" indicate that the suspect could be the highest 'potential serial killer' in Sri Lanka. The importance of the establishment of a National Criminal Investigating Centre is suggested to investigate such unsolved crimes.

Keywords: Serial killer, Cooling off period, Rituals, Signature, Displaying, Souvenirs

\section{Introduction}

The most practical definition of a serial murder is three or more independent, planned murders committed by the same individual or individuals, and separated by a "cooling-off" period (1). According to this definition, it is the "cooling-off" period that separates serial killers from other types of multiple murderers (1).

From 2010 - 2011, a series of beggars were found to have been killed with head injuries, on the pavements of Colombo city and suburbs.
General public were thoroughly disturbed by the reports in the media. Some believed that this was an attempt to eliminate beggars from the Colombo city. In one occasion, even a complaint was made to an international human rights organisation alleging lackadaisical attitude of police on such murders.

This study analysed the medico-legal aspects of this series of killings to determine the nature and characteristics of the killer. 


\section{Methodology}

Data of beggars who were killed with head injuries in the pavements of Colombo and suburbs were collected from 2010 January to 2011 December. The data were collected from media reports, crime scene data of Scene of Crime Officers (SOCO), police records, court records and from clinical examination and investigation of the alleged perpetrator.

Secondary data were collected from journals, text books, internet etc. Analysis of the features of the murders and the suspect was done and compared with the reported incidents of serial killings in medical literature.

\section{Results}

There were 14 murders in 9 towns. They were as follows;

$1^{\text {st }}$ murder - At Wellawatta, a male beggar was alleged to have been killed with head injuries from a granite stone while sleeping. Autopsy was done on $10^{\text {th }}$ April 2010 and the cause of death (COD) was blunt force trauma to head.

$2^{\text {nd }}$ murder - A female beggar was found dead at Kotahena with head injuries. Autopsy was done on $13^{\text {th }}$ of April 2010 and the COD was blunt force trauma to the head.

$3^{\text {rd }}$ male beggar was found murdered at Kotahena on the $1^{\text {st }}$ of May 2010 and the $4^{\text {th }}$ male beggar was found murdered at Slave Island on the $13^{\text {th }}$ of May 2010. Large blood stained granite stone was found near the $3^{\text {rd }}$ body (Picture). The autopsy reports revealed the same cause of death for both cases.

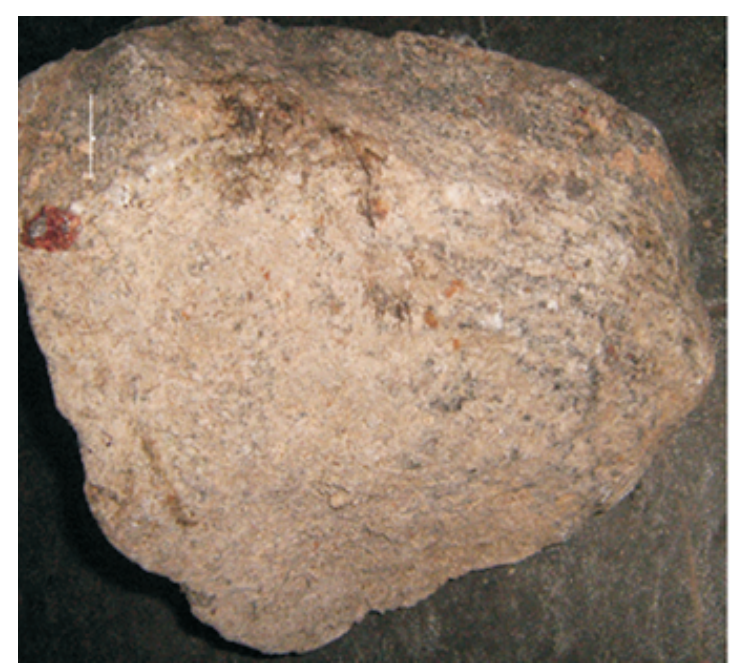

Picture: The blood stained granite stone $5^{\text {th }}$ murder - Another female beggar was found murdered at Colpetty with head injuries. The autopsy was done on $14^{\text {th }}$ May 2010 and the COD was blunt force trauma to head.

Four more $\left(6^{\text {th }}-9^{\text {th }}\right)$ male beggars were murdered at Slave Island on $15^{\text {th }}$ of June 2010, at Mount Lavinia on $28^{\text {th }}$ of June 2010, at Kotahena on $7^{\text {th }}$ of September 2010 and at Paliyagoda on $16^{\text {th }}$ of July 2011 respectively in a similar manner. The autopsy reports revealed the CODs as blunt force trauma to head.

$10^{\text {th }}$ murder - A drunken male was found killed with head injuries at Paliyagoda. The relatives of the deceased complained to an international human rights organization of alleged lackadaisical attitude of the authorities regarding these killings. The autopsy done on $21^{\text {st }}$ July 2011 revealed the COD as blunt force trauma to head.

$11^{\text {th }}$ murder - Body of a male beggar was found at Moratuwa on the $16^{\text {th }}$ of August 2011, about 4.00am. An eye witness stated that he had seen a man, who had his hands raised towards the sky for a while and then assaulted another beggar who was sleeping alone, robbed him and then walked away. This was the only instance where an eye witness was available. He had followed the murderer about $1 \mathrm{~km}$ until he was threatened. The autopsy was done on $16^{\text {th }}$ August 2011 and the COD again was blunt force trauma to head.

Three more $\left(12^{\text {th }}-14^{\text {th }}\right)$ male beggars were found murdered at Paliyagoda on the $19^{\text {th }}$ of September 2011, at Kiribathgoda on $22^{\text {nd }}$ of September 2011 and at Kelaniya on the $2^{\text {nd }}$ of October 2011, respectively. The autopsy reports revealed the CODs as blunt force trauma to head.

Out of 14 deaths, 13 were beggars (11 men) and one was a drunken man sleeping on the pavement. All had been killed probably while sleeping on the pavements. The alleged mechanism of death was an assault with heavy stones on head. In all cases, the COD had been blunt force trauma to head. Only one case had an eye witness. No suspect was arrested in these homicides.

According to the description of the eye witness, there was definite "cooling-off" period in the homicide No. 11. In other cases, the potential shortest coolingoff period is one day and the longest could be as long as 10 months. All 14 dead bodies were not moved away from the site of killing. 
On $30^{\text {th }}$ of November 2011, at 2.30am a beggar was arrested while standing near a concrete block on the pavement at Mount Lavinia. He was produced before the author and was referred for Psychiatrist assessment. Psychiatric assessment was incomplete as he pretended to be dumb. He appeared calm and innocent.

He was reproduced from the remand prison and was reviewed on $24^{\text {th }}$ of February 2012 by the author. He claimed that the scar of a cut injury found on the postero-lateral aspect of the upper part of the neck was caused by an assault with a knife by another beggar in 2001.

He disclosed that on the day of the arrest, he was about to kill a beggar who was sleeping alone on the pavement. Further, he said that he killed all above 14 victims by dropping heavy stones on their head. He said that he tried to sexually abuse one of the female victims.

Psychiatrist assessment revealed "anti-social personality traits" in the suspect and he was sent to the National Institute of Mental Health, Angoda, Sri Lanka for inward observations.

Finally, the suspect had shown the crime scenes accurately to the investigators.

\section{Discussion}

These murders were 'independent', because there was no relationship among the victims and the victims to the suspect except for the fact that the victims were beggars. According to the definition of 'serial murder' the 'planning' is defined as any action committed by an offender in preparation of a murder and involves the accumulation of items for use in the abduction, murder, disposal and selection of a victim (1). In this series, all the cases were well 'planned', such as killing in the mid night while sleeping alone on the pavement in order to avoid eye witness.

According to the description of the eye witness, there was definite 'cooling off period' in the $11^{\text {th }}$ homicide. In all the other cases too, a potential 'cooling off' periods were present.

Fourteen 'independent', 'planned' murders with 'cooling-off periods' indicate that this suspect could be a serial killer in Sri Lanka who killed the highest number of victims.
This is not the first time that serial killers are reported in Sri Lanka. In 2003 a mobile vendor, from Madugoda, Kandy, killed several women. He could be the first serial murderer in the recent criminal history of Sri Lankan (2). The said person had visited houses to sell domestic items between $10.00 \mathrm{am}$ 12.00 noon and when he found a suitable opportunity he used to kill women mostly by strangulation. He had derived sadistic satisfaction by killing these women (2).

In 2004, an army officer, who was suffering from post-traumatic stress and personality disorder following frontal lobe injury caused by a fragment of a grenade, killed five people.

In 2011-2012, Kahawatta in Ratnapura District became under mass fear following mysterious murders. At least seven elderly women were killed and some of the victims had been raped by an unknown killer. Later, the Police arrested several suspects alleged to be connected with these murders. But the Police Department had not sought assistance from Psychologists / Psychiatrists to determine whether these suspects were serial murderers (2).

For comprehensive understanding of serial murder, investigators must review crime-scene photographs, police reports, laboratory reports, media accounts of cases, behavioral characteristics of murderers and victimology information, interact with other parties and interview the offenders as well (3). That was the methodology applied in the investigation of this case series.

The perpetrator of serial murder may not appear like a conventional criminal. Instead, can appear calm and well-mannered (3). The perpetrator in this series too presented calm, quiet and innocent.

All researches are in agreement that the majority of serial murderers are male and have a criminal history (4), exactly as seen in this case.

After committing a murder, the serial killer is not emotionally shocked by the feelings of guilt instead, the perpetrator is emotionally numbed (4). According to the description of the eye witness as well as clinical examination findings, this suspect too displayed similar features.

Most studies have found that the majority of the victims of serial murder were strangers to the offenders. There is no prior relationship between the 
victim and the attacker (4). In this series, though the victims were fellow beggars, there had been no prior relationship with them and the victims were strangers to the killer.

Studies of serial murderers have reported several methods of killing used by offenders, including strangulation (both manual and ligature), stabbing, cutting, blunt-force trauma and firearms. Majority use strangulation or stabbing (5). But in this series, a single method had been used. That is blunt force trauma to head by a stone.

There are two basic body disposal scenarios; either leave at the site of killing or move away from the site of killing. If the offender leaves the victim at the scene, the victim's body can be left as it is or the offender may position the body in a bizarre or suggestive manner or the offender may attempt to conceal the victim at the scene (5). If the offender moves the body away from the murder site, one of the three scenarios can occur: the victim can be dumped, concealed, or displayed. Many serial murder crimes involve more than one crime scene or event site (5). But in this case series, the suspect left the body at the site of killing.

Many serial offenders reflect unusual behaviour that can be attributed to their fantasies such as displaying the victim's body and/ or removal of souvenirs from the scene (6). In this case series no special displaying or removal of souvenirs occurred.

Other features generally found with serial murder are method of operation (modus operandi), ritual and signature (7).

"Rituals" are the symbolic acts reflective of behavior committed by the offender during the course of the crime that are not necessary for the successful completion of the crime (7). In this case, the eye witness had seen the suspect raising his hands to the sky for some time before committing the crime. This could be considered a 'ritual'.

'Signature' is defined as the unique combination of method of operation and ritual that allows one serial case to be linked to others (7). All the cases in this series possessed a signature. All victims were killed probably while sleeping on the pavement by assaulting with heavy stones on head.

Most of the serial killers suffer from Anti-Social Personality Disorders. There are many reasons why serial killers commit murders. Eg: profit, passion, hatred, power or domination, revenge, opportunism, fear, contract killing, desperation, compassion, ritual etc (5). In this case series, he accepted that he did these murders with anger to take the revenge of the cut injury to his neck caused by a fellow beggar in 2001. Anger motivated serial killings are often directed toward a targeted segment of the community (5). In this series, the target group was beggars.

Majority of serial killers kill the victim for sexual motivations (5). In this study, such motivation was noted only in the homicide number 5 .

According to the Anomie Theory, serial killers lack any bonds tying them to the society. They feel isolated, alienated and rejected by the society ( 8 ) as seen in this case.

It creates immense difficulties for the medico-legal community to investigate, identify and prosecute a serial murderer. The medico-legal community should seek the assistance and expertise of professionals including Forensic Psychiatrists.

Awareness among the community plays a key role in prevention of crimes committed especially by the deviant killers. It is each and everyone's duty to be cautious and vigilant and in the same time to maintain the optimal social equilibrium to prevent such crimes.

Similar to the National Child Protection Authority (NCPA), a National Criminal Investigation Centre with a database on crime records is an essential institute for the country. This is with a view to collect reports, maintain records, analyse all unsolved crimes, provide information for investigators and law makers.

\section{Conclusions}

Features such as male gender, murdering strangers, past criminal history, 'rituals' and 'signature' favour the suspect to be a serial killer. Displaying of dead bodies and removal of souvenirs were not evident in this case. Fourteen independent, planned murders were executed with cooling-off periods indicate that the suspect could be the highest potential serial killer in Sri Lanka.

The importance of establishment of a National Criminal Investigation Centre to investigate in to such unsolved crimes is reiterated. 


\section{Acknowledgment}

T. Sugathapala, Chief Inspector and Officer In charge of Crimes, Police Station, Mount Lavinia, Sri Lanka, for collecting samples.

\section{Reference}

1. Byard R, Corey T, Henderson C. Jason Payne-James. Encyclopedia of forensic and legal medicine. (Vol 4). Amsterdam; Boston: Elsevier Academic Press; 2005. 48-52.

2. Jayatunge RM, Serial Killers and the Sri Lankan Society, www.lankaweb.com/news/serial-killers-and-the-SriLankan-society (accessed 22.01.2011).

3. Keppel RD, Birnes WJ. The Psychology of Serial Killer Investigations, The Grisly Business Unit. San Diego, CA: Academic Press; 2003.
4. Ochberg FM, Brantley AC, Hare RD, et al. Lethal predators: psychopathic, sadistic, and sane. International Journal of Emergency Mental Health 2003; 5: 12136.

5. Geberth VJ, Turco RN. Antisocial personality disorder, sexual sadism, malignant narcissism, and serial murder. Journal of Forensic Science 1997; 42: 4960.

6. Dietz PE. Mass, serial and sensational homicides. Bulletin of the New York Academy of Medicine 1987; 62: 47791.

7. Keppel RD. Signature Killers. New York: Pocket Books; 1997.

8. Smith MD, Zahn MA (eds.) (1999) Homicide: A Source Book of Social Research. Thousands Oaks, CA: Sage; 1999. 